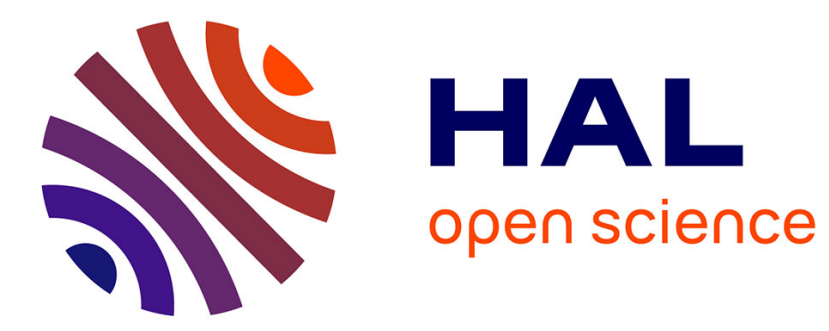

\title{
Combustion and oxidation kinetics of alternative gas turbines fuels
}

Pierre-Alexandre Glaude, Baptiste Sirjean, René Fournet, Roda Bounaceur, Matthieu Vierling, Pierre Montagne, Michel Molière

\section{- To cite this version:}

Pierre-Alexandre Glaude, Baptiste Sirjean, René Fournet, Roda Bounaceur, Matthieu Vierling, et al.. Combustion and oxidation kinetics of alternative gas turbines fuels. Proceedings of ASME, 2014, Paper No. GT2014-25070, pp. V03AT03A001; 10 p. 10.1115/GT2014-25070 . hal-01070016

\section{HAL Id: hal-01070016 https://hal.science/hal-01070016}

Submitted on 8 Oct 2014

HAL is a multi-disciplinary open access archive for the deposit and dissemination of scientific research documents, whether they are published or not. The documents may come from teaching and research institutions in France or abroad, or from public or private research centers.
L'archive ouverte pluridisciplinaire HAL, est destinée au dépôt et à la diffusion de documents scientifiques de niveau recherche, publiés ou non, émanant des établissements d'enseignement et de recherche français ou étrangers, des laboratoires publics ou privés. 


\title{
Combustion and oxidation kinetics of alternative gas turbines fuels
}

\author{
Pierre-Alexandre Glaude, Baptiste Sirjean, René Fournet, Roda Bounaceur \\ LRGP CNRS, Université de Lorraine \\ 1, rue Grandville - BP 20451 - 54001 NANCY - France \\ Matthieu Vierling, Pierre Montagne, Michel Molière \\ GE Energy Product-Europe, \\ 20 avenue de Maréchal Juin, BP 379, 90007 Belfort, France
}

\begin{abstract}
Heavy duty gas turbines are very flexible combustion tools that accommodate a wide variety of gaseous and liquid fuels ranging from natural gas to heavy oils, including syngas, LPG, petrochemical streams (propene, butane...), hydrogenrich refinery by-products; naphtha; ethanol, biodiesel, aromatic gasoline and gasoil, etc. The contemporaneous quest for an increasing the panel of primary energies leads manufacturers and operators to explore an ever larger segment of unconventional power generation fuels. In this moving context, there is a need to fully characterize the combustion features of these novel fuels in the specific pressure, temperature and equivalence ratio conditions of gas turbine combustors using e.g. methane as reference molecule and to cover the safety aspects of their utilization.

A numerical investigation of the combustion of a representative cluster of alternative fuels has been performed, namely two natural gas fuels of different compositions, including some ethane, a process gas with a high butane content in, oxygenated compounds including methanol, ethanol, and DME (dimethyl ether). Sub-mechanisms have specifically been developed to include the reactions of $\mathrm{C}_{4}$ species. Major combustion parameters, such as auto-ignition temperature (AIT), ignition delay times (AID), laminar burning velocities of premixed flames, adiabatic flame temperatures, and $\mathrm{CO}$ and NOx emissions have then been investigated. Finally, the data have been compared with those calculated for methane flames.

These simulations show that the behaviors of alternative fuels markedly differ from that of conventional ones. Especially, DME and the process gases appear to be highly reactive with significant impacts on the auto-ignition temperature and flame speed data, which justifies burner design studies within premixed combustion schemes and proper safety considerations. The behaviors of alcohols (especially methanol) display some commonalities with those of conventional fuels. In contrast, DME and process gas fuels develop substantially different flame temperature and NOx generation rates than methane. Resorting to lean premix
\end{abstract}

conditions is likely to achieve lower NOx emission performances. This review of gas turbine fuels shows for instance that the use of methanol as a gas turbine fuel is possible with very limited combustor modifications.

\section{INTRODUCTION}

Currently, the demand for energy sees a sustained increase, while some fossil fuel resources (oil) are dwindling while others (natural gas) are far from being ubiquitous. It becomes therefore interesting to contemplate using alternative fuels such as biomass derived ones, in some power generation applications. In addition, some industrial processes yield as byproducts some gaseous or liquid streams that are difficult to sell outside or utilize but in combustion. Throughout the history of combustion engines, the heavy duty gas turbine (GT) stands out as the most fuel-flexible prime mover. This type of energy converter is suited for numerous alternative fuels that include: natural gas, liquefied petroleum gas, coal and biomass-derived syngases, and a great variety of process byproducts with diverse compositions (hydrogen, carbon monoxide, olefins, etc.) [1]-[2]. For instance, process gas fuels provide a promising portfolio of alternative fuel opportunities in the major sectors of the industry. In an increasingly uncertain fuel environment, the strong match between gas turbine capabilities and most industrial energy schemes offer a wide perspective of business opportunities. However, the replacement of conventional fuels by such fuel candidates requires preliminary studies to ensure that their physicochemical behavior is fully compatible with the intended applications: qualifying the suitability of such fuels may require extensive testing [3][4]. For instance, from a safety point of view, the ability to compare the reactivity of an alternative fuel with that of natural gas taken as base line fuel is important to anticipate possible self-ignition hazards in pipes or during accidental contacts with hot walls. As far as combustion is concerned, specific considerations relate mainly to the change in flame speeds and temperatures, which can create instabilities (flashbacks, transitions towards detonations), flame blow-off or holding issues. The position 
of the flame in the combustion chamber, the gas flow patterns and the mixing with secondary air can then be affected, which is likely to entail $\mathrm{CO} / \mathrm{UHC}$ emission excursions or distorted heat transfers with potential local overheating. Combustion temperatures affect also nitrogen oxides formation (NOx). The use of very lean mixtures, as close as possible to the LFL (Lower Flammability Limit) without bordering blow out conditions, can make it possible to both reduce flame front temperatures and NOx emission and avoid the risks of flashbacks.

The purpose of this study is to simulate the oxidation and combustion processes of main alternative fuels under gas turbine operation conditions, i.e. at high temperature and pressure. Even though these conditions have been already explored in some works available in the literature, a deeper and more consistent knowledge of the trends is necessary for both safety concerns and GT operation characterization. While the team has devoted a previous study to the combustion of DME [5], the present paper ambitions to provide a theoretical approach to the combustion behavior and emissions indices of eight fuels belonging to three categories: pure alkanes (methane and ethane), natural gas fuels (two different compositions), a process gas, and oxygenated fuels, including methanol and two biofuels: ethanol and DME. The surrogates of natural mimic gases from Pittsburgh (85\% of methane, $15 \%$ of ethane) and Indonesia $(90 \%$ methane, $5 \%$ ethane, $3 \%$ propane, $2 \% n$ butane). The process gas involves $27.4 \%$ of $n$-butane, 45.2 of 1-butene, and $27.4 \%$ of 2-butene. The team has investigated the parameters that are important for process safety and combustion behavior. Auto-ignition temperature (AIT) and auto-ignition delays (AID) of the fuels represent paramount data for instance in fuel purge design and within all safety approaches. Adiabatic flame temperatures allow an evaluation of NOx emission trends during the combustion when switching from methane to another fuel. Finally, the laminar burning velocity is a key input in the design of combustors, and will be determined from a detailed kinetic calculation, from which $\mathrm{NO}$ and $\mathrm{CO}$ emissions will be also evaluated.

Whereas some of these parameters are available for standard room temperature and atmospheric pressure conditions, little is known as to the actual conditions developed in GT combustion. For instance, AITs in air are essentially available at atmospheric pressure. Table 1 summarizes these data for some molecules of interest [6], and show that heavier alkanes display significantly lower AIT than methane that is rather unreactive at low temperature. One can note the very low AIT of DME, in contrast with ethanol, although both have the same raw chemical formula; the handling of DME requires therefore special care. AIT is known to decrease with pressure, even though very few tabulated data are available.

Auto-ignition delay times have been studied more extensively in the literature. In the case of methane and light alkanes and alkenes, many determinations were performed in shock tubes or rapid compression machines, but often with highly diluted fuels [7][8][9]. In a recent work devoted to oxygenated fuel, Kumar and Sung [10] have studied the auto-ignition of methanol in a rapid compression machine over a pressure range of 7-30 bar and a temperature range of $850-1100 \mathrm{~K}$.
Table 1: Auto-ignition temperature of pure fuels (air; $1 \mathrm{~atm}$ ) [6]

\begin{tabular}{|c|c|}
\hline methane & $853 \mathrm{~K}$ \\
\hline Ethane & $763 \mathrm{~K}$ \\
\hline propane & $753 \mathrm{~K}$ \\
\hline$n$-butane & $693 \mathrm{~K}$ \\
\hline 1-butene & $658 \mathrm{~K}$ \\
\hline 2-butene & $708 \mathrm{~K}$ \\
\hline methanol & $783 \mathrm{~K}$ \\
\hline ethanol & $763 \mathrm{~K}$ \\
\hline DME & $623 \mathrm{~K}$ \\
\hline
\end{tabular}

The auto-ignition of ethanol in stoichiometric conditions and at 10 bar has been studied in shock tube by Cancino et al. [11]. As far as DME is concerned, Cook et al. [12] have studied the auto-ignition delay of a mixture containing $1 \%$ of this ether in air between $1200 \mathrm{~K}$ and $1500 \mathrm{~K}$, using a shock tube, while Mittal et al. [13] have investigated a lower temperature range $(615-730 \mathrm{~K})$ with pressures ranging from 10 to 15 bar, using a rapid compression machine. The specific low temperature chemistry of DME oxidation, involving peroxide functional groups, explains its high reactivity at low temperature as compared with that other light oxygenates such as ethanol. This specific mechanism involves also a negative temperature coefficient region (NTC) in which the reactivity drops off when the temperature increases, which is likely to entail undesired complex effects such as cool flames. In high pressure and high temperature combustions as encountered in gas turbines, the formation of thermal NOx obeys the Zeldovich mechanism. Flame temperature represents here the most significant parameter, which governs NOx. Therefore the estimation of the adiabatic flame temperature allows a useful comparison of the NOx emission indices of various fuels [14]. More precise evaluations require dynamic parameters such as the laminar burning velocities. Whereas numerous data exist for methane at $298 \mathrm{~K}$ and $1 \mathrm{~atm}$, higher temperatures and pressures have been much little investigated. Veloo et al. [15] have made a comparative study of the laminar burning velocity of methane, ethane, methanol, and ethanol at $343 \mathrm{~K}$, under atmospheric pressure. Whatever the equivalence ratio, methane has the lowest burning rate, while ethane has the fastest in lean conditions, and oxygenates in rich conditions. Recently, data have been proposed for methane and light alkanes at pressure up to 10 bars and temperatures up to $573 \mathrm{~K}$ [16-18]. Ethanol has been studied up to 5 bar at $373 \mathrm{~K}$ [19], while the burning velocities of DME were measured at $298 \mathrm{~K}$ and up to 10 bar by Qin and $\mathrm{Yu}[20]$.

Whereas many studies deal with engine emissions as a function of fuel formulation, test fields or lab studies representative of the gas turbine combustion are very scarce. Le Cong and Dagaut [21] studied NOx emissions from the combustion of natural gas in a jet stirred reactor under 20 bars from 800 to $1300 \mathrm{~K}$ in presence of steam. The effect of $\mathrm{H}_{2} \mathrm{O}$ on NOx formation was investigated numerically and showed that the reduction of NOx emissions is mainly due to dilution and thermal effects. In the case of premixed ethane flames, Reisel and al. [22] measured by laser induced fluorescence 
the NO concentrations in the post-flame region $(1600<\mathrm{T}<$ $1850 \mathrm{~K})$, at high pressure $(1<\mathrm{P}<14.6 \mathrm{~atm})$ and found that higher pressure led to higher amounts of NO.

\section{KINETIC MODELING}

Several kinetic models for the oxidation and the combustion of light hydrocarbons have been proposed in the literature. A popular mechanism is "GRI-mech" [23], optimized for the simulation of high temperature methane combustion. The combustion of natural gas, as a mixture of light hydrocarbons, is the subject of "GDF-Kin" [24] and Konnov's base [25] which have been regularly up-dated. Recently, Metcalfe et al. have proposed a new reaction base for $\mathrm{C}_{0}-\mathrm{C}_{2}$ species validated against a wide range of experimental data [8] and which includes a number of recent theoretical evaluations of rate constants. While hydrocarbons have been widely studied, only a few numbers of mechanisms contain sub-mechanisms covering the combustion of ethanol [26,27] or DME [28,29], especially if one looks for a mechanism explicitly validated for this last molecule. In order to keep consistency with previous works [5,30], to allow comparisons with the combustion of methane and to include NOx chemistry, the choice made in the present work has been to use the model developed by Konnov [25] as it has been validated for many $\mathrm{C}_{1} / \mathrm{C}_{2}$ hydrocarbons and oxygenated compounds. This mechanism includes up-dated NOx chemistry and has also been validated against ignition delay times, products mole fractions in reactors and burning velocities for many reactants. Ethanol chemistry was extended previously toward low chemistry by the inclusion of theoretically investigated reaction pathways, which involve reactions between radicals deriving from ethanol and molecular oxygen [30]. These reactions are necessary to achieve a correct prediction of low temperature parameters such as AIT or auto-ignition delay times. DME chemistry, which is not included in the original mechanism by Konnov, was added from the work of Zhao et al. [29], which can be taken as the "state of the art" chemistry for DME. This sub-mechanism includes reactions in the low temperature range (i.e. below $800 \mathrm{~K}$ ) that involves the formation of hydroperoxides responsible for some specific behaviors such as cool flames or auto-ignition.

A third sub-mechanism has been added to account for the reactions of $n$-butane and butenes that are not included in the model by Konnov. These reactions are automatically generated by the computer package EXGAS for an oxygen $/ n$ butane mixture $[31,32]$. This software developed by our team produces a comprehensive primary mechanism, where the only molecular reactants to be considered are oxygen and the initial organic compounds (here $n$-butane). The additions of alkyl radicals to oxygen molecules and the subsequent reactions leading to the formation of oxygenated compounds such as peroxides, aldehydes, ketones, and cyclic ethers, which are important below $1000 \mathrm{~K}$, are considered to properly predict the low temperature chemistry, which is important for safety concerns. These reactions are representative of the low temperature reactivity that contributes namely to the low AIT and ignition delay times of DME. More specifically, it is well known that the oxidation of hydrocarbons at low temperature follows a general scheme described by the following reactions:

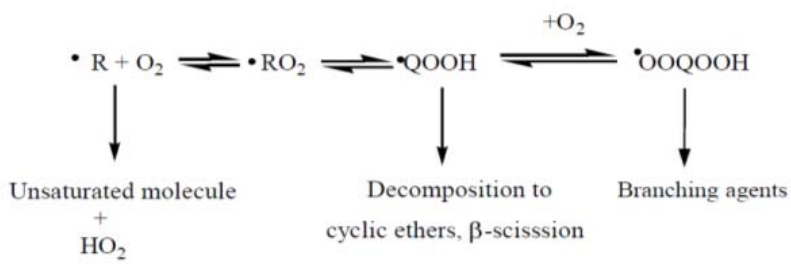

The final mechanism contains 181 species that are involved in 1434 reactions. Performances of these mechanisms were checked against some typical experimental results from the literature, such as flame speed and ignition delay times in the case of methane, ethane and oxygenated fuels and satisfactory results were obtained. Simulations were performed using the CHEMKIN II software [33] developed for the resolution of the mass and energy equations relevant to main laboratory reactors. In particular SENKIN, which is dedicated to the simulation of internal combustion engines, was used for the calculation of ignition delay times and the determination of AITs. PREMIX was used to simulate the premixed laminar flat flames, corresponding to a plug flow of gas taking into account the axial diffusion.

\section{RESULTS AND DISCUSSION \\ Auto-Ignition Temperatures (AIT)}

AITs have been calculated by mimicking the Standard ASTM E 659-78 which considers that there is auto-ignition if a flame is visible at last 10 minutes after the load of the reagents in a silica glass cylinder of $500 \mathrm{~cm}^{3}$. In the calculations, auto-ignition occurrence was assumed when a $400 \mathrm{~K}$ increase of the temperature was reached. Calculations assume a constant volume and a typical heat loss rate through glass walls $\left(\mathrm{h}=19 \mathrm{~W} \mathrm{~m}^{-2} \mathrm{~K}^{-1}\right)$. It is important to stress the point that this simple $0 \mathrm{D}$ simulation method is essentially intended to provide semi quantitative trends but do not ambition to capture the extreme complexity of the real autoignition experiments, especially the heat and convective mass transfer processes inside the test cylinder. Calculations have been performed to determine the auto-ignition temperature of the various fuels and blends under $1,11.5$, and 16 bars, as a function of the equivalence ratio. While the calculations at 1 bar are performed to provide a reference case, the 11.5 and 16 bars cases are relevant to cover leakages events, purging processes as well as the conditions at combustor inlet for the E-class and F-class gas turbines respectively.

Figure 1 shows the AIT obtained through a dichotomy ("ignites/does not ignite") method, for the 8 selected fuels with a $2.5 \mathrm{~K}$ range of accuracy. As already stated, AIT at atmospheric pressure is a key safety parameter in case of any fuel leak close to a hot wall. It has been found that alkanes have fairly high self ignition temperature, methane beeing the less reactive. AITs decrease at higher equivalence ratios, the effect of the fuel concentration conpensating the decrease in oxygen content. Ethane is more reactive and drives to some extent the reactivity of natural gas. The butenes-rich mixture ("the process gas") is significantly more reactive than saturated hydrocarbons, by around $50 \mathrm{~K}$. 

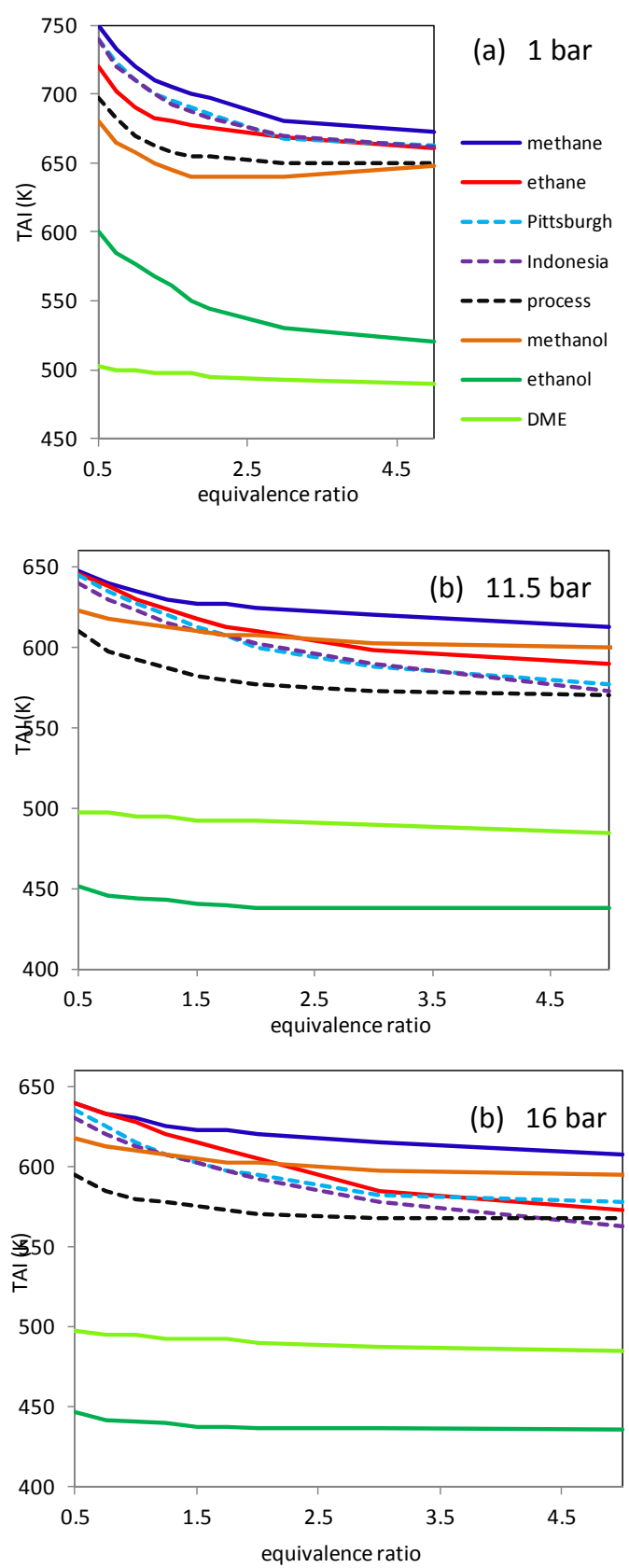

Figure 1: Minimum auto-ignition temperature for seven alternative fuels and methane as a function of the equivalence ratio: (a) 1 bar, (b) 11.5 bars, (c) 16 bars

In contrast, oxygenated compounds and in particular ethanol and DME ignites at temperatures lower by c.a. 200K. This comes from the easier initiation steps due to weaker chemical bonds in the molecules and to the low temperature chemistry, which involves the formation of very reactive peroxides. When increasing the pressure (Fig. 1b and c), AIT decreases for alkenes and natural gases, mostly for lean mixtures, while rich mixtures appear to be less sensitive. AITs of oxygenates are conversely less sensitive to pressure: ethanol and DME display even nearly constant AIT data. Another important point is the significantly higher reactivity of the process gas as compared with conventional fuels: this difference is explained by the double bond that renders the alkene molecules more vulnerable to oxygen attacks.

\section{Auto-Ignition Delay Times (“AID”)}

AID calculations of the fuels of interest have been based on adiabatic constant pressure conditions. The order of magnitude is also an important safety parameter in case of accidental leakage or faulty air intake in a fuel pipe during a purge. Figure 2 shows the ignition delay data calculated at $350^{\circ} \mathrm{C}-11.5$ bars and $400^{\circ} \mathrm{C}-16$ bars, as a function of the initial pressure and equivalence ratio.
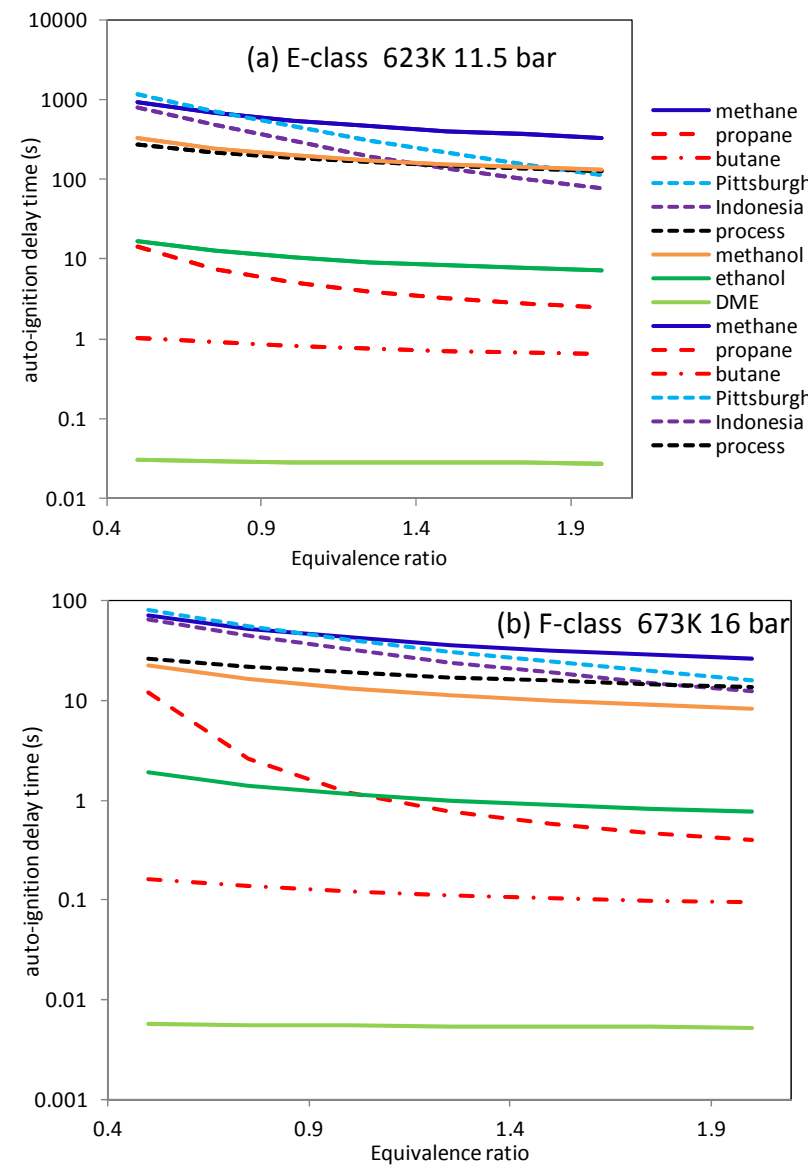

Figure 2: Ignition delay times as a function of equivalence ratio for: (a) an initial temperature of $350^{\circ} \mathrm{C}$ and 11 bars, (b) an initial temperature of $400^{\circ} \mathrm{C}$ and 16 bars.

The same trends as for AITS are observed for the ignition delay times. When moving from methane to higher alkanes contained in natural gas, such as $n$-butane, the ignition delay times drop off. Even small amounts of propane and butane in a natural gas fuel enhance its reactivity (e.g. the Indonesian NG). Oxygenated fuels and, to a lesser extent, the process gas, auto-ignite also much faster than conventional fuels. This is the reason why premixed combustion systems that are traditionally used as low NOx combustion technology for conventional natural gas must be carefully re-evaluated before switching to an alternative fuel. Auto ignition delay times at a given air/fuel ratio strongly decreases from an Etype to an F-type gas turbine, mostly because of the higher 
initial temperature. One can note that oxygenates are also more sensitive to temperature increases than hydrocarbons.

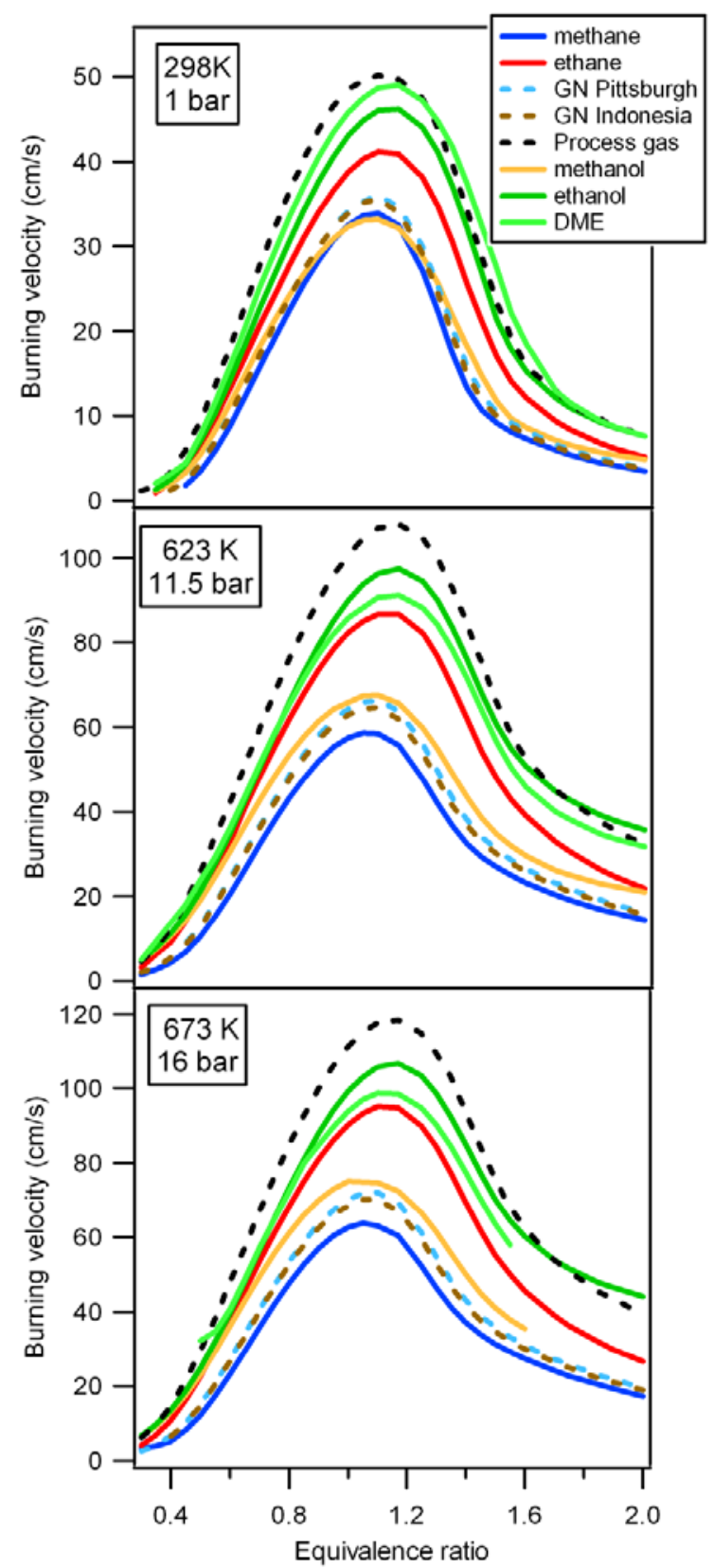

Figure 3: Laminar burning velocities as a function of equivalence ratio under the different studied conditions

\section{Laminar burning velocities}

Laminar premixed flames have been simulated in the conditions that prevail at the inlet of (i) E-class GT combustors (around 11.5 bar, $623 \mathrm{~K}\left(350^{\circ} \mathrm{C}\right)$ ), and (ii) F-class GT combustors (around 16 bars, $673 \mathrm{~K}\left(400^{\circ} \mathrm{C}\right)$ ). Calculations have been performed for a freely propagating, $15 \mathrm{~cm}$-long flame. Figure 3 shows the laminar burning velocities (UL) of the various fuels of the present study. The results reveal the enhancing influence of increasing the fresh gas temperature and the inhibiting effect of increasing their pressure. The maximum burning velocities are obtained at an equivalence ratio around 1.1 , and slightly above for oxygenated fuels. Table 2 shows the values for lean mixtures $(\phi \approx 0.5)$, which are more representative of typical premix combustion in gas turbine: the flame speed is then in the range of 10 to $30 \mathrm{~cm} / \mathrm{s}$, with only little differences between E-class and F-class.

As seen above for the auto-ignition properties, the behaviors of most alternative fuels are quite different from that of a conventional one, exhibiting higher flame velocities, whichever the initial pressure and temperature data. The process gas reaches the highest flame speed, due to its high olefin content. Conversely, methanol shows a behavior comparable to those of conventional fuels, due to its low heating value. It appears therefore that it would be relatively easy to switch a gas turbine to methanol.

Table 2: Flame speed of the fuels at equivalent ratio 0.5

\begin{tabular}{|c|c|c|c|}
\hline Fuel & 1atm, 298K & E-class & F-class \\
\hline Methane & 3.4 & 10.4 & 12.2 \\
\hline Ethane & 6.6 & 20.1 & 22.8 \\
\hline GN Pittsburgh & 4.3 & 13 & 15.0 \\
\hline GN Indonesia & 4.3 & 12.8 & 14.8 \\
\hline Process gas & 9.3 & 25.7 & 29.6 \\
\hline Methanol & 5.5 & 19.1 & 23.0 \\
\hline Ethanol & 7.0 & 21.2 & 25.0 \\
\hline DME & 7.7 & 23.8 & 26.2 \\
\hline
\end{tabular}

\section{Flame temperature}

Flame temperature is a very important parameter that strongly drives the formation of pollutants, especially nitrogen oxides. One must not confuse it with the "firing temperature" or "turbine inlet temperature" that influences GT performances and hot gas path materials technology.

Figure 4 shows the flame temperature of the burnt gases in the three configurations studied. As for flame speed, the maximum flame temperature is obtained for slightly rich mixtures, at an equivalence ratio around 1.05-1.1, because of the lower impact of dilution by nitrogen when the amount of air decreases. At the strict stoichiometric conditions, the rate of the endothermal molecular dissociations is also at its maximum which tends to depress the temperature. Flame temperature is significantly higher in F-class GTs than in Ecalls as the intaking combustion air is hotter. Conversely, calculations show that the pressure affects very little the flame temperature.

These values were compared to the adiabatic equilibrium temperature obtained by Gibbs enthalpy minimization by means of the software Gaseq [34]. It appears that flame temperatures are very close to that of the thermochemical equilibrium. Only mixtures richer than 1.7 show a significant difference of a few tens of Kelvin. However, as it will be shown below, the flames reach their thermal equilibrium but not their chemical equilibrium in terms of combustion products distribution. 


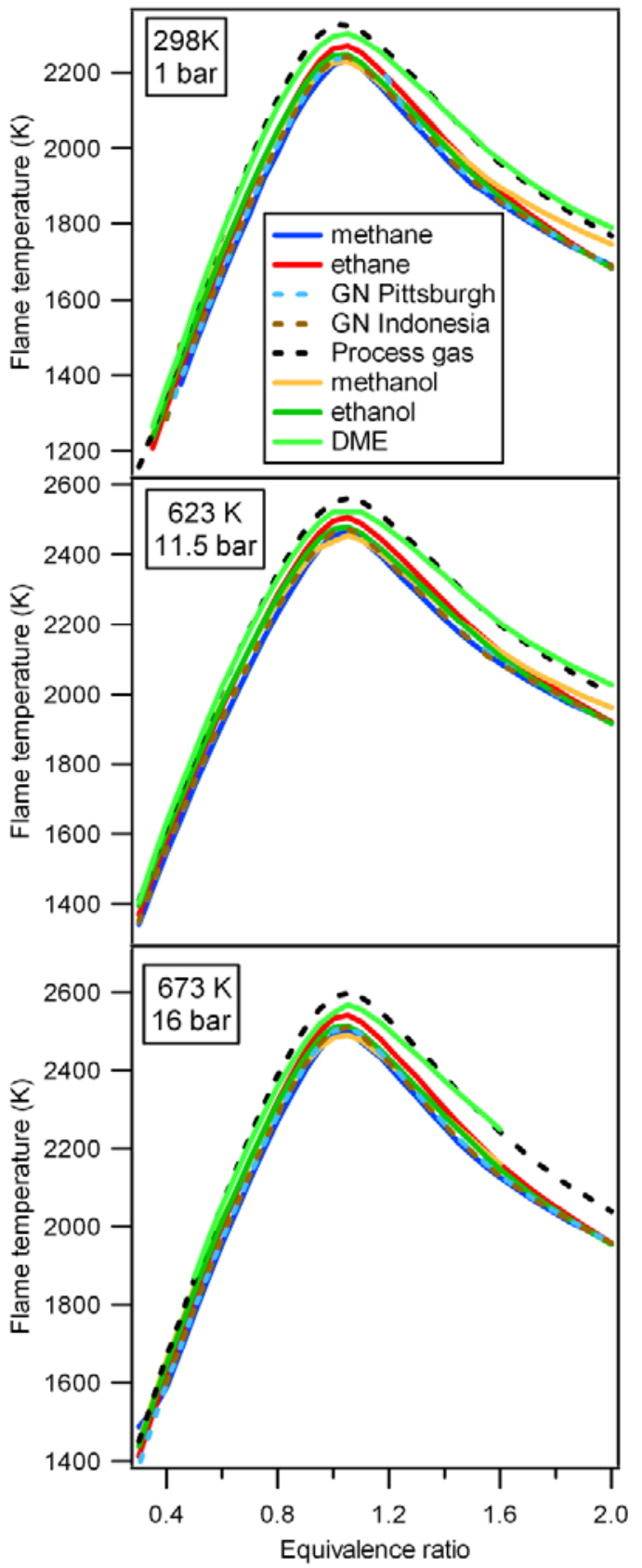

Figure 4: Flame temperatures as a function of equivalence ratio under the three sets of conditions studied

The results show that alcohols have flame temperatures comparable to those of conventional fuels, contrary to DME that develops significantly higher temperatures. This is consistent with the respective values of the heating values of these fuels and thermochemical equilibrium data. The process gas has a flame temperature even higher, because of the unsaturated bond present in the butenes species, which increases their heating value [14]. Table 3 gives the flame temperature for an equivalence ratio of 0.5 which is not far from of gas turbine operation.
Table 3: Flame temperature of the fuels at equivalent ratio 0.5

\begin{tabular}{|c|c|c|c|}
\hline Fuel & 1atm, 298K & E-class & F-class \\
\hline Methane & 1476 & 1737 & 1779 \\
\hline Ethane & 1518 & 1780 & 1819 \\
\hline GN Pittsburgh & 1486 & 1748 & 1789 \\
\hline GN Indonesia & 1487 & 1749 & 1791 \\
\hline Process gas & 1572 & 1824 & 1867 \\
\hline Methanol & 1549 & 1803 & 1845 \\
\hline Ethanol & 1537 & 1794 & 1837 \\
\hline DME & 1581 & 1834 & 1872 \\
\hline
\end{tabular}

\section{Formation of pollutants}

NOx and $\mathrm{CO}$ are the most critical pollutants emitted by gas turbines. It must be stressed beforehand that the present approach, which is based on simple laminar premixed flames, aims at providing a general comparison between methane and alternative fuels emissions based on simplified equivalence ratio considerations but does not ambition to predict the actual emissions of the highly turbulent gas turbine flames, for which an elaborated CFD-chemistry coupling would be required. The above flame simulations provide the amounts of $\mathrm{CO}$ and $\mathrm{NO}$ at the flame outlet. Figures 5 shows the amounts of $\mathrm{CO}$ obtained for each fuel in the various flame conditions. In the flame, $\mathrm{CO}$ is first produced and is oxidized afterwards into $\mathrm{CO}_{2}$ by $\mathrm{OH}$ radicals. One can first note that the $\mathrm{CO}$ content in the burnt gas dramatically increases with the equivalence ratio $(\phi)$, even when staying well below the stoichiometry. While the high excess of oxygen present in lean mixtures allows an easy oxidation of $\mathrm{CO}$ to $\mathrm{CO}_{2}$, this is no longer the case in richer mixtures. The log scale used in the first (atmospheric conditions) and third (F-class gas turbines) configurations represented in figure 5 illustrates this key effect of temperature. The linear scale used for the second configuration (E-class) shows that the differences between fuels are almost independent from the equivalence ratio. As for the flame temperature, the $\mathrm{CO}$ amount is minimal for methane and maximal for the process gas and for DME that generates four times as much $\mathrm{CO}$ as natural gas. Whatever the equivalence ratio, the oxygenated fuels tend to generate more $\mathrm{CO}$. Note that the calculated amounts of $\mathrm{CO}$ allow comparisons of fuels but are obtained in the burnt gases close to the maximum flame temperature and are higher than the actual amount at the exhaust of the combustion chamber since a large part of $\mathrm{CO}$ oxidizes further to $\mathrm{CO}_{2}$ when the temperature decreases.

When one compares these results with the thermochemical equilibrium compositions calculated with Gaseq [34], using the same thermochemical data of molecules as in the kinetic mechanism, one can note that the $\mathrm{CO}$ amount predicted by the kinetic calculations are slightly above the equilibrium in lean condition and below the equilibrium value in rich conditions. In lean conditions, the kinetic limitations lead to higher $\mathrm{CO} / \mathrm{CO}_{2}$ ratio. The access to the full equilibrium would typically require much longer residence times in the combustion chambers than the actual ones. 

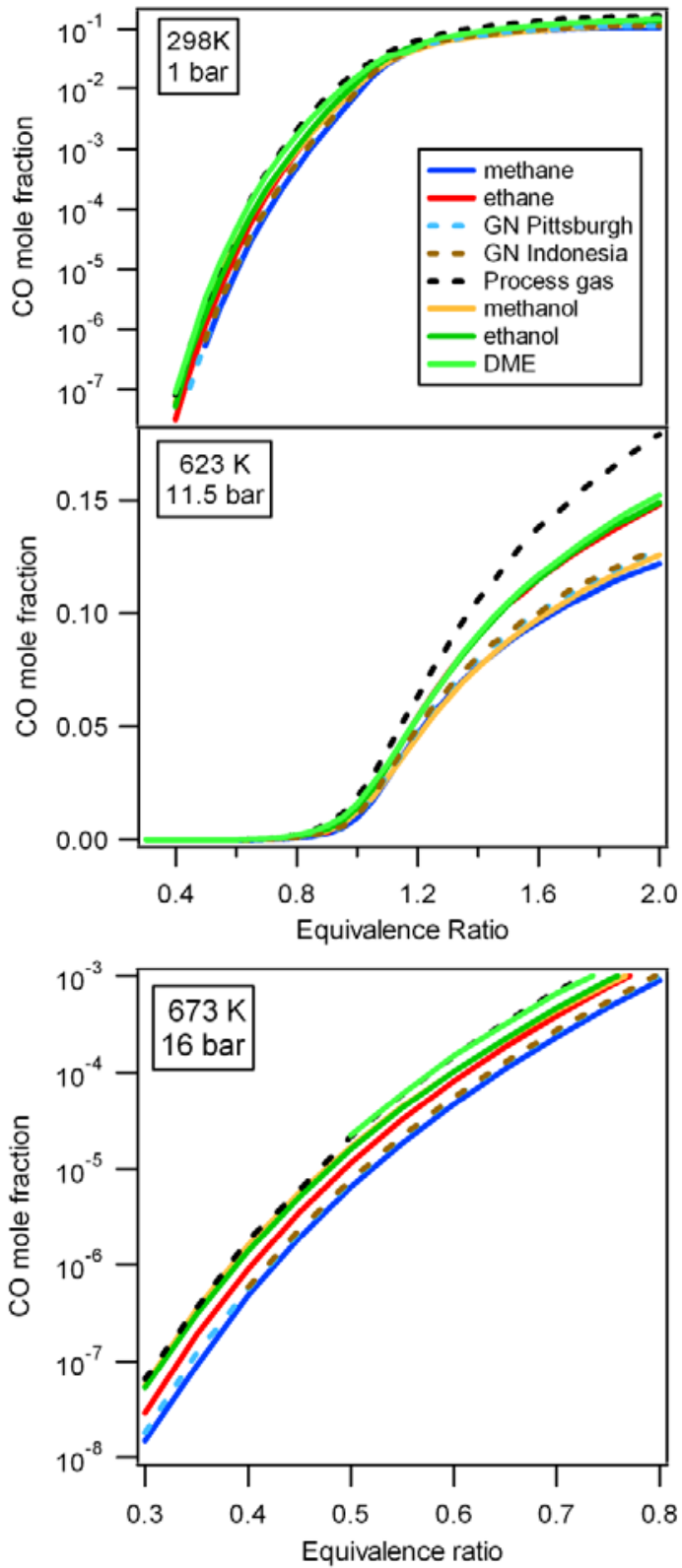

Figure 5: CO mole fraction in the burnt gases as a function of equivalence ratio under the different studied conditions.

Thermal and chemical equilibrium are somewhat disconnected since the small difference in product distributions has a critical impact on the $\mathrm{CO}$ and $\mathrm{NOx}$ emission but has a virtually negligible effect on the global reaction heat release and thus hardly affects the flame temperature. In rich conditions, the global oxidation process is slower and some hydrocarbon intermediates are not completely consumed at the exit of the flame, leading in this case to a lower CO amount. Finally the above considerations must be strongly relativized by the fact that the equivalence ratio of GT premixed flames never exceeds 0.5 .

The amounts of NO produced in the different flames are shown in figure 6. Linear scales are used for the atmospheric and E-class cases, while a log scale and a reduced range of
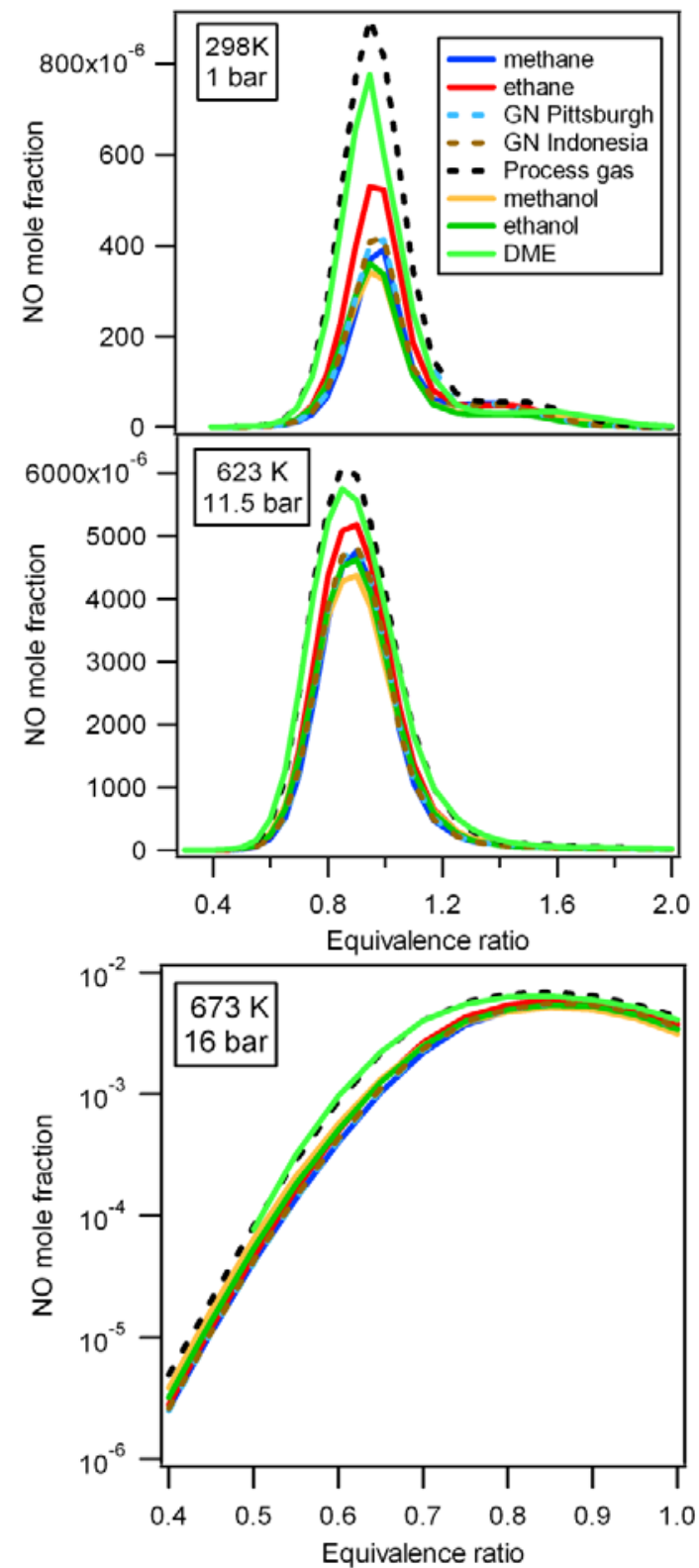

Figure 6: NO mole fraction in the burnt gases as a function of equivalence ratio under the different studied conditions.

equivalence ratios is used in the case of the F-class to give a better view of more realistic equivalence ratio conditions. NO formation shows in all cases a very marked maximum for an equivalence ratio lying at around 0.95 (for the atmospheric conditions) and 0.85 (for the $\mathrm{E}$ and F-class conditions). This shift of the maximum amount to lower equivalence ratios is due to the higher $\mathrm{N}_{2}$ and $\mathrm{O}$-atom concentration in the leaner mixture. A higher initial temperature strongly promotes the thermal NO formation. Methane flames produce the lowest amount of NO whatever the conditions. Natural gas fuels behave similarly, while ethane, DME and especially the process gas lead to higher values. These trends are explained directly by the higher flame temperatures. Table 4 shows the NO concentration in the burnt gases of the various flames at 
equivalence ratio 0.5 . When comparing to thermochemical equilibrium, it appears that for equivalence ratios below 1.3, the amount of NO is lower than at equilibrium, the difference increasing when the mixtures become leaner. For $\phi=0.5$, the difference reaches two orders of magnitude. In this range of equivalence ratios, the formation of NO is strongly limited by the kinetics even though the temperature is the same in laminar premixed flame as at the thermochemical equilibrium. Again, the typical residence time in the flame is too short to reach the NO equilibrium.

Table 4: NO amount (ppmv) at the end of the different flames at equivalent ratio 0.5

\begin{tabular}{|c|c|c|c|}
\hline Fuel & 1atm, 298K & E-class & F-class \\
\hline Methane & 0.70 & 17 & 41 \\
\hline Ethane & 0.80 & 20 & 46 \\
\hline GN Pittsburgh & 0.68 & 17 & 41 \\
\hline GN Indonesia & 0.70 & 18 & 42 \\
\hline Process gas & 1.34 & 35 & 83 \\
\hline Methanol & 0.74 & 28 & 64 \\
\hline Ethanol & 0.81 & 23 & 54 \\
\hline DME & 1.15 & 32 & 77 \\
\hline
\end{tabular}

Some practical engineering correlations have been proposed in the literature to link NO emissions in gas turbines using diffusion flame and the stoichiometric adiabatic flame temperature [35]. The same correlation used for the premixed flames simulated here leads to a strong overprediction of NO, by about an order of magnitude. Keeping the same expression, an optimization was done to determine the parameters for the prediction of $\mathrm{NO}$ in the burnt gases at an equivalence ratio around 0.5 from the flame temperature at the same equivalence ratio. Note that the temperature of the burnt gases is very close to the adiabatic flame temperature in these conditions. The correlation is then as follows:

$$
\mathrm{NO}(\mathrm{ppmv})=\frac{1.55 \times 10^{-5} 10^{\left(5.32 \times 10^{-3} \times \mathrm{T}_{\mathrm{fl}, 0.5}\right)}}{\mathrm{T}_{\mathrm{fl}, 0.5}}
$$

where $\mathrm{T}_{\mathrm{fl}, 0.5}$ denotes the flame temperature at equivalence ratio 0.5 . This correlation allows a better evaluation of the NO formation for the different inlet pressure and temperature studied here for the lean conditions of interest in gas turbine combustion.

\section{CONCLUSION}

This work aimed at providing a primary comparison of the combustion behavior of various alternative GT fuels with that of methane and natural gas, based on kinetic simulations using appropriate, up-to-date flame chemistries. The main alternative fuels studied were: ethanol, methanol, DME and a butane-rich process gas. The results show interesting trends, namely the higher reactivity of DME and process gas that display low auto-ignition temperatures and higher flame speed. The behavior of alcohols (especially methanol) is closer to that of conventional fuels. In terms of flame temperature and pollutant formation, DME and process gases lead to significantly higher values than the levels generated by methane or natural gas flames. Whatever the fuel, the leanest mixtures allow a limitation of emissions of NOx. It should be noted that burnt gases in flames are very far from the thermodynamic equilibria. When the equivalence ratio equals 0.5 , which approaches modern gas turbine configurations, the $\mathrm{NO}$ and $\mathrm{CO}$ emissions found are comparable with those awaited. These results namely indicate that the use of methanol as a fuel for a gas turbine is possible with slight modifications compared to the technology for conventional GT fuels.

\section{REFERENCES}

[1] Moliere M., Vierling M., et Symonds R., 2010, " Interest for liquid fuels in power generation gets renewed», Proceedings of the ASME Turbo Expo, p. 39-46.

[2] Lieuwen T., McDonell V., Petersen E., et Santavicca D., 2008, «Fuel Flexibility Influences on Premixed Combustor Blowout, Flashback, Autoignition, and Stability », J. Eng. Gas Turbines Power, 130(1), p. 011506-10.

[3] Andersson M., Larsson A., Lindholm A., et Larfeldt J., 2012, «Extended fuel flexibility testing of siemens industrial gas turbines: A novel approach », Proceedings of the ASME Turbo Expo, p. 759-766.

[4] Glaude P. A., Fournet R., Warth V., et Molière M., 2005, «Stability of Olefin-Containing Process Gases as an Alternative Fuel for Gas Turbines », Ind. Eng. Chem. Res., 44(12), p. 4212-4220.

[5] Glaude P.-A., Fournet R., Bounaceur R., et Molière M., 2011, «DME as a potential alternative fuel for gas turbines: A numerical approach to combustion and oxidation kinetics », Proceedings of the ASME Turbo Expo, p. paper GT2011-46238.

[6] Guibet J.-C., 1997, Carburants et moteurs: technologies, énergie, environnement, Editions Technip.

[7] Simmie J. M., 2003, «Detailed chemical kinetic models for the combustion of hydrocarbon fuels ", Progress in Energy and Combustion Science, 29(6), p. 599-634.

[8] Metcalfe W. K., Burke S. M., Ahmed S. S., et Curran H. J., 2013, «A Hierarchical and Comparative Kinetic Modeling Study of C1 - C2 Hydrocarbon and Oxygenated Fuels », International Journal of Chemical Kinetics, 45(10), p. 638-675.

[9] Heyberger B., Belmekki N., Conraud V., Glaude P.A., Fournet R., et Battin-Leclerc F., 2002, " Oxidation of small alkenes at high temperature », Int. J. Chem. Kinet., 34(12), p. 666-677.

[10] Kumar K., et Sung C.-J., 2011, «Autoignition of methanol: Experiments and computations », International Journal of Chemical Kinetics, 43(4), p. 175-184.

[11] Cancino L. R., Fikri M., Oliveira A. A. M., et Schulz C., 2011, « Ignition delay times of ethanol-containing multi-component gasoline surrogates: Shock-tube experiments and detailed modeling », Fuel, 90(3), p. 1238-1244. 
[12] Cook R. D., Davidson D. F., et Hanson R. K., 2009, «High-Temperature Shock Tube Measurements of Dimethyl Ether Decomposition and the Reaction of Dimethyl Ether with $\mathrm{OH} »$, J. Phys. Chem. A, 113(37), p. 9974-9980.

[13] Mittal G., Chaos M., Sung C.-J., et Dryer F. L., 2008, "Dimethyl ether autoignition in a rapid compression machine: Experiments and chemical kinetic modeling », Fuel Processing Technology, 89(12), p. 1244-1254.

[14] Glaude P. A., Fournet R., Bounaceur R., et Molière M., 2010, «Adiabatic flame temperature from biofuels and fossil fuels and derived effect on NOx emissions », Fuel Processing Technology, 91(2), p. 229-235.

[15] Veloo P. S., Wang Y. L., Egolfopoulos F. N., et Westbrook C. K., 2010, «A comparative experimental and computational study of methanol, ethanol, and n-butanol flames », Combustion and Flame, 157(10), p. 1989-2004.

[16] Han P., David Checkel M., Fleck B. A., et Nowicki N. L., 2007, «Burning velocity of methane/diluent mixture with reformer gas addition », Fuel, 86(4), p. 585-596.

[17] Lowry W. V., 2011, «Laminar Flame Speed Measurements and Modeling of Pure Alkanes and Alkane Blends at Elevated Pressures », Journal of Engineering for Gas Turbines and Power, 133(9), p. 091501.

[18] Troshin K. Y., Borisov A. A., Rakhmetov A. N., Arutyunov V. S., et Politenkova G. G., 2013, «Burning velocity of methane-hydrogen mixtures at elevated pressures and temperatures », Russian Journal of Physical Chemistry B, 7(3), p. 290-301.

[19] Varea E., Modica V., Vandel A., et Renou B., 2012, «Measurement of laminar burning velocity and Markstein length relative to fresh gases using a new postprocessing procedure: Application to laminar spherical flames for methane, ethanol and isooctane/air mixtures "), Combustion and Flame, 159(2), p. 577-590.

[20] Qin X., et Ju Y., 2005, « Measurements of burning velocities of dimethyl ether and air premixed flames at elevated pressures », Proceedings of the Combustion Institute, 30(1), p. 233-240.

[21] Cong L., et Dagaut P., 2009, «Experimental and detailed modeling study of the effect of water vapor on the kinetics of combustion of hydrogen and natural gas, impact on NOx », Energy and Fuels, 23(2), p. 725-734.

[22] Reisel J. R., Carter C. D., Laurandeau N. M., et Drake M. C., 1993, «Laser-Saturated Fluorescence Measurements of Nitric Oxide in Laminar, Flat, C2H6/O2/N2 Flames at Atmospheric Pressure », Combustion Science and Technology, 91(4-6), p. 271-295.
[23] Smith G. P., Golden D., Frenklach M., Moriarty N., Eiteneer B., Goldenberg M., Bowman C., Hanson R., Song S., Gardiner W., Lissianski V., et Qin Z., « GRI-Mech 3.0 », http://www.me.berkeley.edu/gri_mech/.

[24] De Ferrières S., El Bakali A., Lefort B., Montero M., et Pauwels J. F., 2008, « Experimental and numerical investigation of low-pressure laminar premixed synthetic natural gas/O2/N2 and natural gas/H2/O2/N2 flames ", Combustion and Flame, 154(3), p. 601-623.

[25] Konnov A. A., Barnes F. J., Bromly J. H., Zhu J. N., et Zhang D., 2005, " The pseudo-catalytic promotion of nitric oxide oxidation by ethane at low temperatures », Combustion and Flame, 141(3), p. 191-199.

[26] Marinov N. M., 1999, «A Detailed Chemical Kinetic Model for High Temperature Ethanol Oxidation ", International Journal of Chemical Kinetics, 31(2-3), p. $183-220$.

[27] Saxena P., et Williams F. A., 2007, « Numerical and experimental studies of ethanol flames », Proceedings of the Combustion Institute, p. 1149-1156.

[28] Dagaut P., Daly C., Simmie J. M., et Cathonnet M., 1998, « Oxidation and ignition of dimethylether from low to high temperature (500-1600 K): Experiments and kinetic modeling », Symposium (International) on Combustion, 1, p. 361-369.

[29] Zhao Z., Chaos M., Kazakov A., et Dryer F. L., 2008, « Thermal decomposition reaction and a comprehensive kinetic model of dimethyl ether », International Journal of Chemical Kinetics, 40(1), p. 1-18.

[30] Glaude P. A., Fournet R., Bounaceur R., et Molière M., 2010, «Ethanol as an alternative fuel in gas turbines: Combustion and oxidation kinetics ", Proceedings of the ASME Turbo Expo, p. 555-562.

[31] Buda F., Bounaceur R., Warth V., Glaude P. A., Fournet R., et Battin-Leclerc F., 2005, «Progress toward a unified detailed kinetic model for the autoignition of alkanes from $\mathrm{C} 4$ to $\mathrm{C} 10$ between 600 and $1200 \mathrm{~K}$ », Combustion and flame, 142(1-2), p. 170-186.

[32] Biet J., Hakka M. H., Warth V., Glaude P.-A., et Battin-Leclerc F., 2008, « Experimental and Modeling Study of the Low-Temperature Oxidation of Large Alkanes », Energy Fuels, 22(4), p. 2258-2269.

[33] Kee R. J., Rupley F. M., et Miller J. A., 1993, « Sandia Laboratories Report, S 89-8009B ».

[34] Morley C., 2005, Gaseq, Chemical equilibria in perfect gases v. 0.79 .

[35] Molière M., 2004, «Hydrogen fueled gas turbines: status and prospects », 2nd CAME-GT Conference, Bled, Slovenia. 